\title{
Combined effects of glutathione S-transferase M1 and T1 polymorphisms on risk of lung cancer: evidence from a meta- analysis
}

\author{
Ying Gao ${ }^{1,}{ }^{*}$, Fei $\mathrm{Gao}^{2,}{ }^{*}$, Ting-Ting $\mathrm{Hu}^{3}$, Gang $\mathrm{Li}^{4}$, Yan-Xia Sui ${ }^{5}$ \\ ${ }^{1}$ Department of Radiotherapy Oncology, First Affiliated Hospital of Medical College of Xi'an, Jiao Tong University, Xi'an, \\ Shanxi, China \\ ${ }^{2}$ Department of Neurology, First Affiliated Hospital of Xi'an Medical University, Xi'an, Shanxi, China \\ ${ }^{3}$ Department of Medical, First Affiliated Hospital of Medical College of Xi'an, Jiao Tong University, Xi'an, Shanxi, China \\ ${ }^{4}$ Second Department of Thoracic Surgery, First Affiliated Hospital of Medical College of Xi'an, Jiao Tong University, Xi'an, \\ Shanxi, China \\ ${ }^{5}$ Department of Pathology, First Affiliated Hospital of Medical College of Xi'an, Jiao Tong University, Xi'an, Shanxi, China \\ *These authors contributed equally to this work and should be considered as co-first authors
}

Correspondence to: Ying Gao, email: gaoyyingqw@163.com, togaoying@163.com

Keywords: GSTM1, GSTT1, polymorphism, lung cancer, meta-analysis

Received: September 14, $2016 \quad$ Accepted: February 23, $2017 \quad$ Published: March 06, 2017

Copyright: Gao et al. This is an open-access article distributed under the terms of the Creative Commons Attribution License (CC-BY), which permits unrestricted use, distribution, and reproduction in any medium, provided the original author and source are credited.

\section{ABSTRACT}

Many studies have reported an association between the glutathione S-transferase M1 null and T1 null polymorphisms and lung cancer risk. However, the combined effects of GSTM1 null and GSTT1 null polymorphisms have not been reported previously. We, therefore, performed a meta-analysis to investigate the combined effects. 40 publications with 44 case-control studies were selected in the metaanalysis, including 13,706 cases and 13,093 controls. Significant association was observed between the combined effects of GSTM1 and GSTT1 polymorphisms and lung cancer risk when all the eligible studies were pooled into the meta-analysis. When we performed subgroup analysis, significantly increased lung cancer risk was observed in Caucasians ( -- vs. ++ : OR $=1.23,95 \%$ CI: 1.07 to 1.41), Asians ( - vs. - +: OR $=1.24,95 \%$ CI: 1.10 to 1.41 ; recessive model: $O R=1.45,95 \%$ CI: 1.19 to 1.77 ; dominant model: $\mathrm{OR}=1.53,95 \% \mathrm{CI}: 1.24$ to 1.90$)$, Indians $(--$ vs. ++ : OR $=2.53$, 95\% CI: 1.61 to 3.98; recessive model: OR $=1.69,95 \% \mathrm{CI}: 1.07$ to 2.67 ; dominant model: $\mathrm{OR}=2.11,95 \% \mathrm{CI}: 1.36$ to 3.28 ), hospital-based studies, and populationbased studies. In summary, this meta-analysis indicates that the combined effects of the GSTM1 and GSTT1 polymorphisms are associated with increased lung cancer risk in Asians, Caucasians, and Indians.

\section{INTRODUCTION}

Lung cancer has become the most common cancer and the leading cause of cancer death in the world [1]. There were about 219,440 lung cancer cases and 159,390 deaths expected in the United States in 2009 [2]. In recent years, the incidence of lung cancer in Asia increased rapidly [3]. Tobacco smoking is clearly the strongest risk factor for lung cancer [4]. However, not all smokers develop lung cancer, which indicates that other causes, including genetic susceptibility, may contribute to development of lung cancer [5-6].
Possible lung cancer susceptibility genes have been sought among tumor suppressor genes, DNA repair genes, and genes encoding phase I and phase II enzymes [7]. Glutathione S-transferases (GSTs) comprise a multi-gene family encoding enzymes, is phase II transformation enzymes involved in the detoxification of hazardous agents [8]. Acting nonenzymically, GSTs can modulate signalling pathways of cell proliferation, cell differentiation and apoptosis [9]. GSTs can be classified into at least four genetically distinct groups including Glutathione S-transferase M1(GSTM1) and Glutathione S-transferase T1(GSTT1) [10]. GSTM1 and GSTT1 are 
two of the most important GST variants. GSTM1 located on chromosome 1p13.3 with 10 exons and GSTT1 is mapped at chromosome 22q11.23 and contains six exons. Individuals with the homozygous deletion of the GSTM1 and GSTT1 locus (GSTM1 null and GSTT1 null) have no enzymatic functional activity [11].

To date, some previous meta-analyses have only studied the association between GSTM1and/or GSTT1 alone gene polymorphisms and risk of lung cancer [12-14, 63, 64]. However, the combined effects of GSTM1 and GSTT1 polymorphisms have not been reported previously. In addition, a number of molecular epidemiological studies have been performed to evaluate the association between the combined effects of glutathione S-transferase M1 and T1 polymorphisms and lung cancer risk [15-56]. However, the results were inconsistent or even contradictory. Therefore, we performed a meta-analysis to investigate the combined effects of GSTM1 and GSTT1 and lung cancer risk.

\section{RESULTS}

\section{Literature search and meta-analysis databases}

Relevant publications were retrieved and preliminarily screened. As shown in Figure 1, 672 potentially relevant publications were identified. Of these, 549 publications were excluded after reading the title or abstract because of obvious irrelevance with our study aim (this included review, case reports, metaanalysis, conference abstract, letter, editorial, and other genetic polymorphism). In addition, of these published articles, 2 articles [49, 51] were excluded because of their sample size overlapped with another 2 articles $[41,27]$. As summarized in Supplementary Table 1, 40 publications with 44 case-control studies were selected for the meta-analysis, including 13,706 cases and 13,093 controls. Among these publications, 21 were Caucasians, 14 were Asians, 3 were Indians, 3 were Africans, and 3 were mixed populations. In addition, 7 were Chinese articles and 37 were English articles. Last, 31 were hospital-based studies and 13 were population-based studies.

\section{Quantitative synthesis}

Table 1 lists the main results of the meta-analysis of the association between the combined effects of GSTM1 and GSTT1 polymorphism and lung cancer risk. Significant association was observed between the combined effects of GSTM1 and GSTT1 polymorphism and lung cancer risk $(--$ vs. ++ : OR $=1.58,95 \% \mathrm{CI}$ : 1.34 to $1.87, P<0.001 ;--$ vs. $+-:$ OR $=1.26,95 \% \mathrm{CI}$ : 1.13 to $1.42, P<0.001$; -- vs. $-+:$ OR $=1.26,95 \% \mathrm{CI}$ : 1.08 to $1.48, P=0.004$; recessive model: $\mathrm{OR}=1.27,95 \%$
CI: 1.13 to $1.42, P<0.001$; dominant model: $\mathrm{OR}=1.33$, 95\% CI: 1.19 to $1.48, P<0.001)$ when all the eligible studies were pooled into the meta-analysis. Significant between-study heterogeneity was detected in overall analysis. Hence, then we performed subgroup analysis by ethnicity, significantly increased lung cancer risk was observed in Caucasians ( -- vs. ++ : OR $=1.23,95 \%$ CI: 1.07 to $1.41, P=0.003$, Figure 2$)$, Asians ( -- vs. -+ : $\mathrm{OR}=1.24,95 \% \mathrm{CI}: 1.10$ to $1.41, P=0.001$; recessive model: $\mathrm{OR}=1.45,95 \% \mathrm{CI}: 1.19$ to $1.77, P<0.001$; dominant model: $\mathrm{OR}=1.53,95 \% \mathrm{CI}: 1.24$ to $1.90, P<$ 0.001 , Figure 3 ), Indians ( -- vs. $++:$ OR $=2.53,95 \%$ CI: 1.61 to $3.98, P<0.001$; recessive model: $\mathrm{OR}=1.69$, 95\% CI: 1.07 to $2.67, P=0.025$; dominant model: $\mathrm{OR}=$ $2.11,95 \% \mathrm{CI}: 1.36$ to $3.28, P=0.001)$. In addition, we also performed subgroup analysis by source of controls, significantly increased lung cancer risk was observed in hospital-based studies ( -- vs. ++ : OR $=1.58,95 \% \mathrm{CI}$ : 1.29 to $1.94, P<0.001$; recessive model: $\mathrm{OR}=1.30,95 \%$ CI: 1.14 to $1.48, P<0.001$; dominant model: $\mathrm{OR}=1.36$, 95\% CI: 1.18 to $1.56, P<0.001)$ and population-based studies $(--$ vs. $++:$ OR $=1.58,95 \%$ CI: 1.16 to $2.14, P$ $<0.001$; -- vs. $-+:$ OR $=1.48,95 \%$ CI: 1.12 to $1.94, P=$ 0.006 ; recessive model: $\mathrm{OR}=1.24,95 \% \mathrm{CI}: 1.04$ to 1.49 , $P=0.016$; dominant model: $\mathrm{OR}=1.29,95 \% \mathrm{CI}: 1.07$ to $1.55, P=0.006)$.

\section{Heterogeneity and sensitivity analysis}

Significant heterogeneity was observed in the metaanalysis, as shown in Table 1. Hence, we used metaregression analysis to assess the source of heterogeneity by ethnicity, source of controls, and language. The results indicated that ethnicity, source of control, and language did not contribute to substantial heterogeneity in the metaanalysis. $I^{2}>75.0 \%$ was observed in Asians (- vs. + $+)$, however, when the study of Cao YF et al. [45] was excluded, heterogeneity values dropped in Asians (- vs. $\left.++: I^{2}=72.5 \%\right)$. In addition, exclusion of the study of Cao YF et al. [45] resulted in a statistically significant association between the combined effects of GSTM1 and GSTT1 polymorphisms and lung cancer risk in Asians $(--$ vs. $++:$ OR $=1.91,95 \%$ CI: 1.34 to $2.74, P<0.001)$.

\section{Publication bias}

Using Egger's test, significant publication bias was detected in the meta-analysis (dominant model: $P=$ 0.007). We used the Duval and Tweedie nonparametric "trim and fill" method to adjust for publication bias. Figure 4 lists the Duval and Tweedie nonparametric "trim and fill" methods funnel plot. The pooled results did not change between the combined effects of GSM1 and $\mathrm{T} 1$ polymorphisms and lung cancer risk in dominant model. 
Table 1: Combined genotype analysis of GSTM1 and GSTT1on risk of lung cancer

\begin{tabular}{|c|c|c|c|c|c|c|c|c|c|c|}
\hline \multirow[t]{2}{*}{ Variables } & \multirow[t]{2}{*}{ Studies } & \multirow{2}{*}{$\begin{array}{l}\text { Cases/ } \\
\text { control }\end{array}$} & \multicolumn{4}{|c|}{ Test of association } & \multicolumn{3}{|c|}{ Test of heterogeneity } & \multirow[t]{2}{*}{ Model } \\
\hline & & & OR & $95 \% \mathrm{CI}$ & $Z$ & $P$ & Chi-squared & $P_{\mathrm{h}}$ & $I^{2}(\%)$ & \\
\hline \multicolumn{11}{|l|}{-- vs. ++} \\
\hline Overall & 34 & $5,886 / 5,224$ & 1.58 & $1.34-1.87$ & 5.34 & $<0.001$ & 78.12 & $<0.001$ & 57.8 & Random effect model \\
\hline \multicolumn{11}{|c|}{ Subgroup analyses by ethnicity } \\
\hline Caucasian & 16 & $2,608 / 2,893$ & 1.23 & $1.07-1.41$ & 2.95 & 0.003 & 17.04 & 0.317 & 12.0 & Fixed effect model \\
\hline Asian & 11 & $2,707 / 1,674$ & - & - & - & - & 42.92 & $<0.001$ & 76.7 & - \\
\hline Indian & 3 & $348 / 391$ & 2.53 & $1.61-3.98$ & 4.02 & $<0.001$ & 1.50 & 0.473 & 0.0 & Fixed effect model \\
\hline \multicolumn{11}{|c|}{ Subgroup analyses by study design } \\
\hline HB & 23 & $1,971 / 2,242$ & 1.58 & $1.29-1.94$ & 4.38 & $<0.001$ & 38.11 & 0.018 & 42.3 & Random effect model \\
\hline PB & 11 & $3,915 / 2,982$ & 1.58 & $1.16-2.14$ & 2.93 & 0.003 & 38.98 & $<0.001$ & 74.3 & Random effect model \\
\hline \multicolumn{11}{|l|}{-- vs. +-} \\
\hline Overall & 23 & $3,309 / 2,063$ & 1.26 & $1.13-1.42$ & 4.02 & $<0.001$ & 23.08 & 0.397 & 4.7 & Fixed effect model \\
\hline \multicolumn{11}{|l|}{-- vs. -+} \\
\hline Overall & 23 & $4,447 / 3,198$ & 1.26 & $1.08-1.48$ & 2.91 & 0.004 & 32.11 & 0.076 & 31.5 & Random effect model \\
\hline \multicolumn{11}{|c|}{ Subgroup analyses by ethnicity } \\
\hline Caucasian & 10 & $1,263 / 1,400$ & 1.15 & $0.86-1.56$ & 0.94 & 0.346 & 17.52 & 0.041 & 48.6 & Random effect model \\
\hline Asian & 10 & $2,948 / 1,592$ & 1.24 & $1.10-1.41$ & 3.42 & 0.001 & 13.48 & 0.142 & 33.2 & Fixed effect model \\
\hline \multicolumn{11}{|c|}{ Subgroup analyses by study design } \\
\hline HB & 17 & $1,514 / 1,569$ & 1.16 & $0.98-1.37$ & 1.76 & 0.078 & 21.78 & 0.150 & 26.5 & Fixed effect model \\
\hline PB & 6 & $2,933 / 1,629$ & 1.48 & $1.12-1.94$ & 2.77 & 0.006 & 9.91 & 0.078 & 49.5 & Random effect model \\
\hline \multicolumn{11}{|c|}{-- vs. $(+-)+(-+)$} \\
\hline Overall & 34 & $8,177 / 6,586$ & 1.27 & $1.13-1.42$ & 4.19 & $<0.001$ & 45.99 & 0.066 & 28.2 & Random effect model \\
\hline \multicolumn{11}{|c|}{ Subgroup analyses by ethnicity } \\
\hline Caucasian & 16 & $3,417 / 3,558$ & 1.09 & $0.97-1.23$ & 1.40 & 0.163 & 20.04 & 0.170 & 25.1 & Fixed effect model \\
\hline Asian & 11 & $4,159 / 2,403$ & 1.45 & $1.19-1.77$ & 3.72 & $<0.001$ & 16.60 & 0.084 & 39.8 & Random effect model \\
\hline Indian & 3 & $348 / 273$ & 1.69 & $1.07-2.67$ & 2.24 & 0.025 & 2.04 & 0.360 & 2.0 & Fixed effect model \\
\hline \multicolumn{11}{|c|}{ Subgroup analyses by study design } \\
\hline HB & 23 & $2,601 / 2,714$ & 1.30 & $1.14-1.48$ & 3.92 & $<0.001$ & 24.48 & 0.323 & 10.1 & Fixed effect model \\
\hline PB & 11 & $5,576 / 3,867$ & 1.24 & $1.04-1.49$ & 2.41 & 0.016 & 19.85 & 0.031 & 49.6 & Random effect model \\
\hline \multicolumn{11}{|c|}{-- vs. $(+-)+(-+)+(++)$} \\
\hline Overall & 44 & $13,706 / 13,093$ & 1.33 & $1.19-1.48$ & 5.11 & $<0.001$ & 79.41 & 0.001 & 45.9 & Random effect model \\
\hline \multicolumn{11}{|c|}{ Subgroup analyses by ethnicity } \\
\hline Caucasian & 21 & $6,771 / 7,545$ & 1.10 & $0.99-1.22$ & 1.86 & 0.063 & 22.73 & 0.302 & 12.0 & Fixed effect model \\
\hline Asian & 14 & $5,766 / 4,337$ & 1.53 & $1.24-1.90$ & 3.95 & $<0.001$ & 40.79 & $<0.001$ & 68.1 & Random effect model \\
\hline Indian & 3 & $632 / 632$ & 2.11 & $1.36-3.28$ & 3.34 & 0.001 & 2.02 & 0.363 & 1.2 & Fixed effect model \\
\hline African & 3 & $219 / 278$ & 1.34 & $0.86-2.10$ & 1.28 & 0.201 & 0.55 & 0.758 & 0.0 & Fixed effect model \\
\hline \multicolumn{11}{|c|}{ Subgroup analyses by study design } \\
\hline HB & 31 & $5,694 / 6,359$ & 1.36 & $1.18-1.56$ & 4.29 & $<0.001$ & 46.4 & 0.028 & 35.3 & Random effect model \\
\hline PB & 13 & $8,012 / 6,734$ & 1.29 & $1.07-1.55$ & 2.72 & 0.006 & 31.87 & 0.001 & 62.3 & Random effect model \\
\hline
\end{tabular}

+- Refers to GSTM1 Present GSTT1 Null; - + refers to GSTM1 Null GSTT1 Present; - - refers to GSTM1 Null GSTT1 Null; ++ refers to GSTM1 Present GSTM1 Present; HB hospital-based studies; PB population-based studies

\section{DISCUSSION}

Lung cancer, accounting for $13 \%$ (1.6 million) of all cancers and $18 \%$ (1.4 million) of all cancer deaths in 2008 , has become the most common cancer in the world [1]. Gene polymorphism factor has been reported to be an important factor which increases the susceptibility of lung cancer. Some genetic polymorphisms alters the enzyme activity and leads to individual differences in the susceptibility to cancer [67]. GSTM1 and GSTT1 null genotype lost enzymatic functional activity, therefore, may increase the risk of lung cancer. To date, a series of previous meta-analysis have only focused on the association between single GSTM1 or GSTT1 gene 
polymorphism and lung cancer risk [12-14, 63, 64]. However, the combined effect of GSTM1 and GSTT1 has not been reported previously. In addition, many studies have been performed to evaluate the association between the combined effects of glutathione S-transferase M1 and T1 polymorphisms and lung cancer risk. However, the results were inconsistent or even contradictory. Therefore, we performed a meta-analysis to investigate the combined effects of GSTM1 and GSTT1 polymorphisms and lung cancer risk.

Significant association was found between the combined effects of GSTM1 and GSTT1 polymorphisms

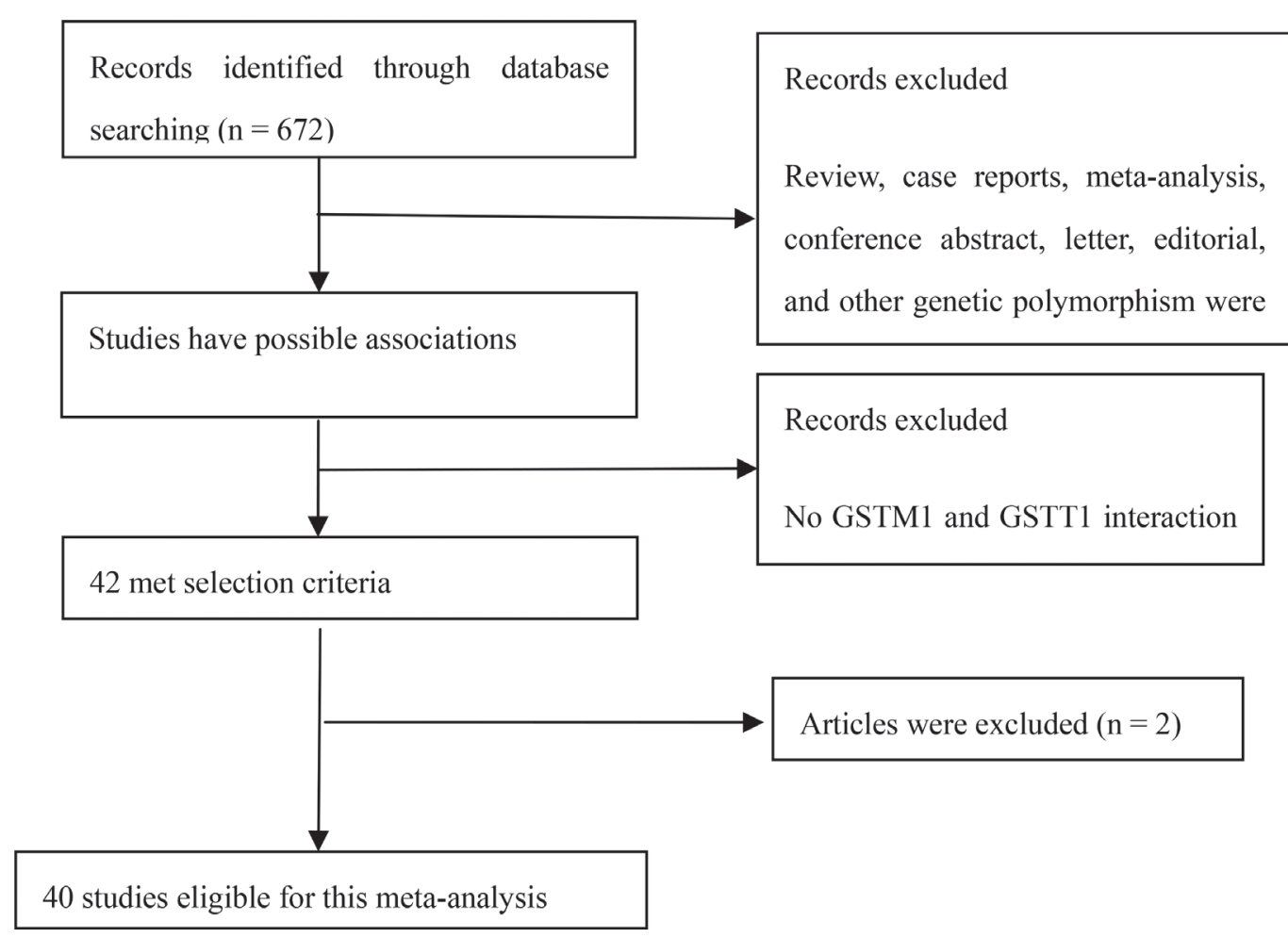

Figure 1: Flow diagram of selection process to identify eligible studies in the meta-analysis.

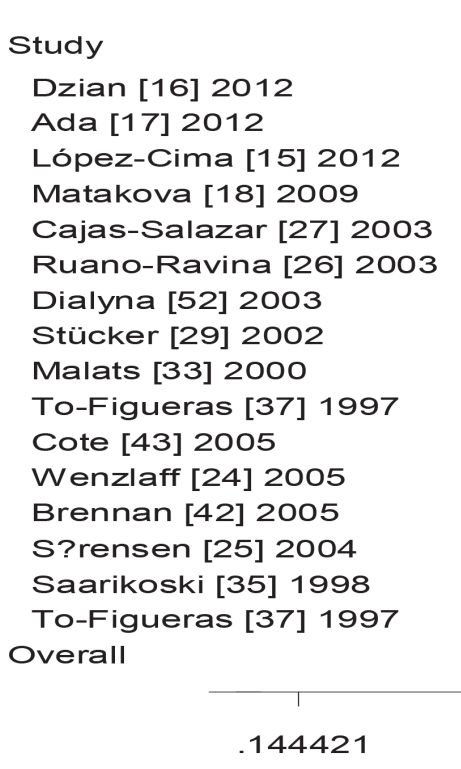

Figure 2: Forest plot of the the combined effects of GSTM1 and GSTT1 polymorphisms and lung cancer risk in Caucasians $(--$ vs. ++$)$.

\begin{tabular}{lr} 
Odds ratio & \\
$\begin{array}{l}\text { OS\% Cl }) \\
1.92(1.02,3.62)\end{array}$ & 3.6 \\
$1.82(0.98,3.39)$ & 4.0 \\
$0.95(0.68,1.34)$ & 17.9 \\
$1.62(0.82,3.21)$ & 3.4 \\
$2.46(1.00,6.04)$ & 1.6 \\
$1.07(0.52,2.22)$ & 3.7 \\
$1.10(0.44,2.79)$ & 2.3 \\
$0.86(0.45,1.66)$ & 5.2 \\
$0.91(0.42,1.98)$ & 3.6 \\
$1.44(0.67,3.09)$ & 3.0 \\
$1.07(0.56,2.03)$ & 4.8 \\
$1.21(0.53,2.79)$ & 2.7 \\
$1.09(0.87,1.38)$ & 36.9 \\
$2.80(1.13,6.92)$ & 1.7 \\
$1.49(0.70,3.16)$ & 2.9 \\
$2.04(0.99,4.20)$ & 2.8 \\
$1.23(1.07,1.41)$ & 100.0 \\
\hline \\
\hline
\end{tabular}

Odds ratio ght

7.9

3.4

1.6

3.7

3.6

3.0

4.8

1.7

2.9

2.8

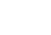
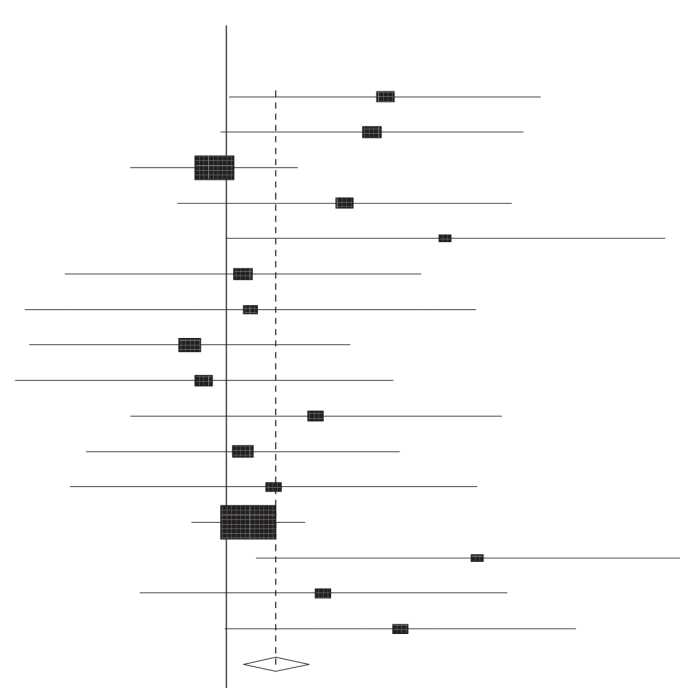

6.92417 
and lung cancer risk when all the eligible studies were pooled into the meta-analysis. When we performed subgroup analysis, significant increased lung cancer risk was observed in Caucasians, Asians, and Indians. It is possible that the effect sizes of genetic factors predisposing to human diseases are different in various ethnic populations [66]. Dzian et al. [16], Matakova et al. [18], and Cajas-Salazar et al. [27] suggested that the combined effects of GSTM1 and GSTT1 polymorphisms increased lung cancer risk in Caucasians. Chen et al.

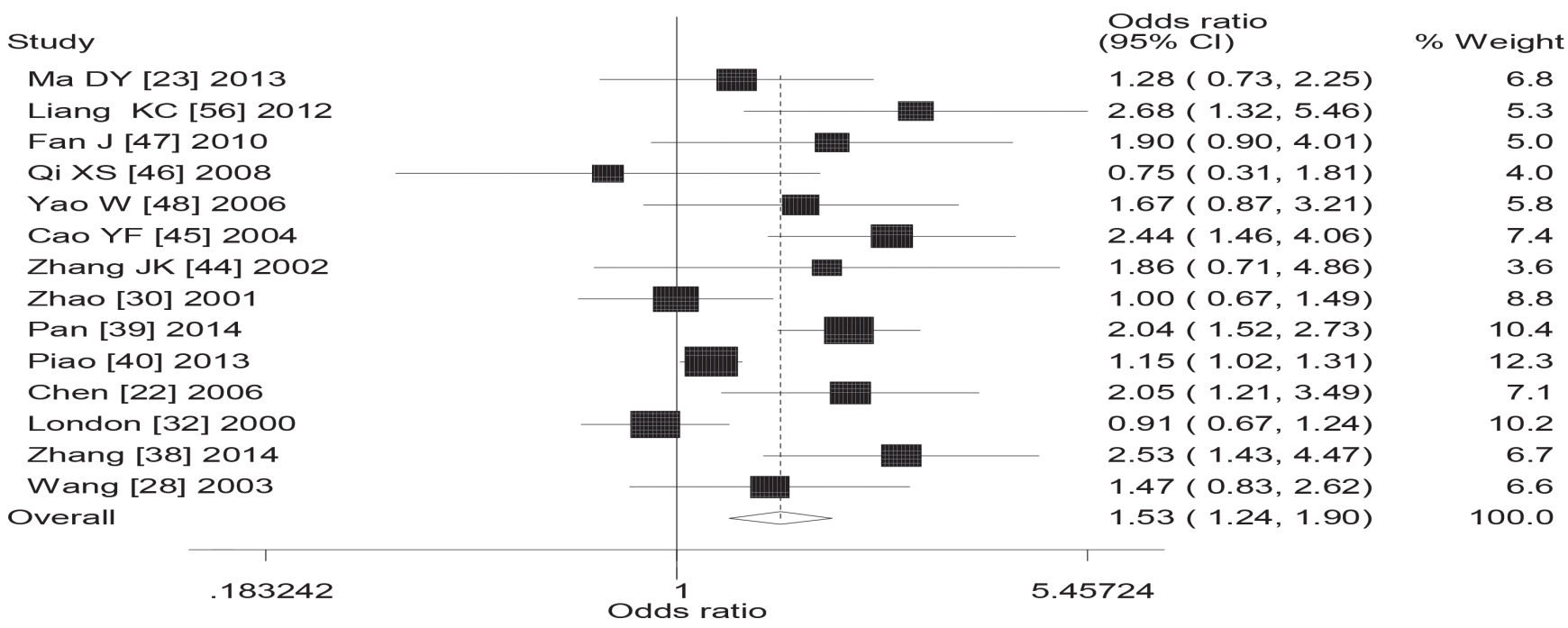

Figure 3: Forest plot of the the combined effects of GSTM1 and GSTT1 polymorphisms and lung cancer risk in Asians (dominant model).

Filled funnel plot with pseudo $95 \%$ confidence limits

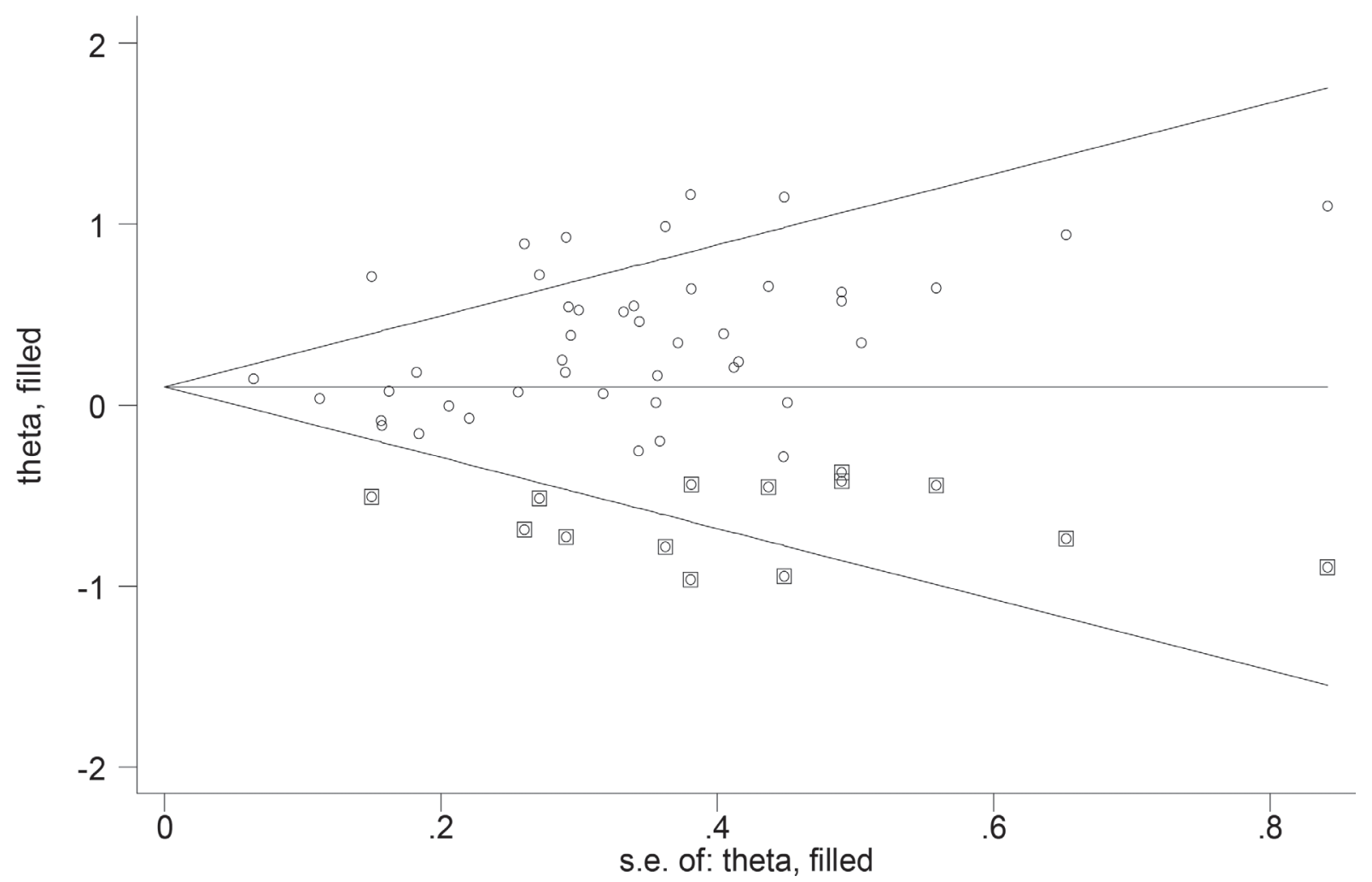

Figure 4: The Duval and Tweedie nonparametric "trim and fill" method's funnel plot of the meta-analysis (dominant model). 
[22], Liang KC et al. [56], Cao YF et al. [45], Pan et al. [39], Piao et al. [40], and Zhang et al. [38] suggested that the GSTM1 and GSTT1 polymorphisms in combination were associated with increased risk factors of lung cancer in Asians. Sharma et al. [31] and Sreeja et al. [41] found that the combined effects of GSTM1 and GSTT1 polymorphisms increased lung cancer risk in Indians. The results of the meta-analysis supported the positive association. However, at any case, the association between the combined effects of GSTM1 and GSTT1 polymorphisms and lung cancer risk in Indians essentially remains an open field, as the number of studies $(n=3)$ is considerably smaller than that needed for the achievement of robust conclusions [65]. When we performed subgroup analysis by source of controls, significantly increased lung cancer risk was also observed in hospital-based studies and population-based studies. The hospital-based studies have some biases because such controls might be a sample of ill-defined reference population. Hence, using a proper population-based study was very important.

In this meta-analysis, several limitations should be acknowledged. First, due to the limited participant data provided by individual studies, we could not examine the interactions among gene-environment. Second, only published articles were included in this study, which may cause publication bias. Third, the controls were not uniformly defined. However, the current meta-analysis has also particular strengths. First, our meta-analysis explores and analyzes the sources of heterogeneity. Second, This is the first meta-analysis to explore the combined GSTM1 and GSTTleffects and lung cancer risk. Third, a metaanalysis is statistically more powerful than any single study. Fourth, the quality of eligible studies met our inclusion criterion in the meta-analysis.

In summary, this meta-analysis indicates that the combined effects of GSTM1 and GSTT1 polymorphisms is associated with increased lung cancer risk in Asians, Caucasians, and Indians. As we only explored the association between two combined genes and lung cancer risk, there is still leaving much to be studied in depth. To further evaluate the effects of gene-gene interaction on lung cancer risk, a population-based study on large size of samples is required.

\section{MATERIALS AND METHODS}

\section{Identification and eligibility of relevant studies}

We searched the electronic databases including PubMed, Embase, Web of Science, and two Chinese databases China National Knowledge Infrastructure (CNKI) and Wanfang Data (the last search update was August 8, 2016) with The following key words ("Glutathione S-transferase M1 or "GSTM1", "Glutathione S-transferase T1 or "GSTT1", "variant" or "variation" or "polymorphism", and "lung". The search was performed without any restrictions on language. In addition to the electronic database search, we reviewed manually the reference lists of retrieved articles to identify additional articles.

\section{Inclusion criteria and data extraction}

The included studies met the following criteria: (1) patients had a diagnosis of lung cancer; (2) evaluated combination effects of the GSTM1 and GSTT1 polymorphisms and lung cancer risk; (3) used case-control or cohort studies; (4) provided sufficient data of combined genotypes for the GSTM1 and GSTT1 polymorphisms in lung cancer patients and controls; (5) reviews, conference abstracts, letters, and editorials were excluded; (5) duplications of previously published data were excluded (if more than one article was published using the same case data, only the article with the largest sample size was selected). The following data were collected from each study: (1) first author's name; (2) year of publication; (3) country of origin; (4) ethnicity; (5) source of controls (population-based controls and hospital-based controls); (6) language; (7) numbers of cases and controls in the combined genotypes for the GSTM1 and GSTT1 polymorphisms whenever possible. Ethnicity was categorized as "Caucasian", "Asian", and "African" (including African Americans). We also considered the samples of studies from India and Pakistan as of "Indian". Last, When one study did not state which ethnic groups was included, or if it was impossible to separate participants according to phenotype, the sample was termed as "mixed population".

\section{Statistical analysis}

The association between the combined effects of GSTM1 and GSTT1 polymorphisms and lung cancer risk was calculated by the crude odds ratios (ORs) as the combined study effect size and summary statistics with $95 \%$ confidence intervals (CI) in a dominant model (- vs. $(+-)+(-+)+(++))$, a recessive model $(--$ vs. $(+-)+(-+))$, and a co-dominant model $(--$ vs. ++ , -- vs. +- , and -- vs. -+$)$. - - represented GSTM1 null GSTT1 null genotype. + - represented GSTM1 present GSTT1 null genotype. - + represented GSTM1 null GSTT1 present genotype. + + represented GSTM1 present GSTT1 present genotype. The significance of the pooled OR was determined by the $Z$-test, and $P<0.05$ was considered as statistically significant. Statistical heterogeneity among studies was assessed by the chi-square-based $Q$ test [57] and $I^{2}$ value [58]. In heterogeneity tests, when $P<0.1$, a random-effects model was used [59], otherwise a fixedeffects model was performed [60]. Meanwhile, if $I^{2} \geq$ $50 \%, 50 \%>I^{2} \geq 25 \%$ or $0<I^{2}<25 \%$, we identified the studies as high, middle or low heterogeneity, respectively. Publication bias was analyzed by Egger's linear regression 
test [61]. If publication bias existed, the Duval and Tweedie nonparametric "trim and fill" method was used to adjust for it [62]. Sensitivity analysis was performed by excluding one study at a time to evaluate the stability of the results. A meta-regression analysis was carried out to identify the major sources of between-studies variation in the results, using the log of the ORs from each study as dependent variables, and ethnicity, language and source of controls as the possible sources of heterogeneity. All statistical tests were performed by STATA version 10.0 (STATA Corporation, College Station, TX).

\section{Abbreviations}

GSTM1, glutathione S-transferase M1; OR, odds ratio; 95\% CI, 95\% confidence interval; HB: hospitalbased controls; PB: publication-based controls.

\section{Authors' contributions}

All authors contributed significantly to this work, Ying Gao and Fei Gao performed the research design and data collection; Ting-Ting Hu and Ying Gao conducted the meta-analysis; Ying Gao, Gang Li, and Yan-Xia Sui wrote the paper and prepared Figures 1-4 and Supplementary Table 1. All authors reviewed the manuscript. Moreover, all authors confirmed the final edition.

\section{CONFLICTS OF INTEREST}

The authors have declared that no competing interests exist.

\section{FUNDING}

This study was supported by National Natural Science Foundation of China (No. 81301937).

\section{REFERENCES}

1. Jemal A, Bray F, Center MM, Ferlay J, Ward E, Forman D. Global cancer statistics. CA Cancer J Clin. 2011; 61:69-90.

2. Jemal A, Siegel R, Ward E, Hao Y, Xu J, Thun MJ. Cancer statistics, 2009. CA Cancer J Clin. 2009;59:225-49.

3. Yang X, Qiu MT, Hu JW, Wang XX, Jiang F, Yin R, Xu L. GSTT1 null genotype contributes to lung cancer risk in Asian populations: a meta-analysis of 23 studies. PLoS One. 2013; 8:e62181.

4. Hu YC, Sidransky D, Ahrendt SA. Molecular detection approaches for smoking associated tumors. Oncogene. 2002; 21:7289-7297.

5. Risch A, Plass C. Lung cancer epigenetics and genetics. Int J Cancer. 2008; 123:1-7.

6. Hecht SS. Tobacco smoke carcinogens and lung cancer. J Natl Cancer Inst. 1999; 91:1194-1210.
7. Reszka E, Wasowicz W. Significance of genetic polymorphisms in glutathione S-transferase multigene family and lung cancer risk. Int J Occup Med Environ Health. 2001; 14:99-113.

8. Hirvonen A, Saarikoski ST, Linnainmaa K, Koskinen K, Husgafvel-Pursiainen K, Mattson K, Vainio H. Glutathione $\mathrm{S}$-transferase and $\mathrm{N}$-acetyltransferase genotypes and asbestos-associated pulmonary disorders. J Natl Cancer Inst. 1996; 88:1853-1856.

9. Dusinska M, Staruchova M, Horska A, Smolkova B, Collins A, Bonassi S, Volkovova K. Are glutathione S transferases involved in DNA damage signalling? Interactions with DNA damage and repair revealed from molecular epidemiology studies. Mutat Res. 2012; 736:130-137.

10. Mannervik B, Awasthi YC, Board PG, Hayes JD, Di Ilio C, Ketterer B, Listowsky I, Morgenstern R, Muramatsu M, Pearson WR, Pickett CB, Sato K, Widersten M, Wolf CR. Nomenclature for human glutathione transferases. Biochem J. 1992; 282:305-306.

11. Kuper H, Tzonou A, Kaklamani E, Hsieh CC, Lagiou P, Adami HO, Trichopoulos D, Stuver SO. Tobacco smoking, alcohol consumption and their interaction in the causation of hepatocellular carcinoma. Int J Cancer. 2000; 85:498-502.

12. Wang Y, Yang H, Wang H. The association of GSTT1 deletion polymorphism with lung cancer risk among Chinese population: evidence based on a cumulative metaanalysis. Onco Targets Ther. 2015; 8:2875-2882.

13. Yang H, Yang S, Liu J, Shao F, Wang H, Wang Y. The association of GSTM1 deletion polymorphism with lung cancer risk in Chinese population: evidence from an updated meta-analysis. Sci Rep. 2015; 5:9392.

14. Liu H, Ma HF, Chen YK. Association between GSTMI polymorphisms and lung cancer: an updated meta-analysis. Genet Mol Res. 2015; 14:1385-1392.

15. López-Cima MF, Alvarez-Avellón SM, Pascual T, FernándezSomoano A, Tardón A. Genetic polymorphisms in CYP1A1, GSTM1, GSTP1 and GSTT1 metabolic genes and risk of lung cancer in Asturias. BMC Cancer. 2012; 12:433.

16. Dzian A, Halasova E, Matakova T, Kavcova E, Smolar M, Dobrota D, Hamzik J, Mistuna D. Lung adenocarcinoma and squamous cell carcinoma in association with genetic polymorphisms of GSTs in Slovak population. Neoplasma. 2012; 59:160-167.

17. Ada AO, Kunak SC, Hancer F, Soydas E, Alpar S, Gulhan M, Iscan M. Association between GSTM1, GSTT1, and GSTP1 polymorphisms and lung cancer risk in a Turkish population. Mol Biol Rep. 2012; 39:5985-5993.

18. Matakova T, Sivonova M, Halasova E, Mistuna D, Dzian A, Berzinec P, Letkova L, Dobrota D. Gene polymorphisms of biotransforming enzymes (GSTs) and their association with lung cancer in the Slovakian population. Eur J Med Res. 2009; 14:275-279.

19. Cabral RE, Caldeira-de-Araujo A, Cabral-Neto JB, Costa Carvalho Mda G. Analysis of GSTM1 and GSTT1 polymorphisms in circulating plasma DNA of lung cancer patients. Mol Cell Biochem. 2010; 338:263-269. 
20. Sobti RC, Kaur P, Kaur S, Janmeja AK, Jindal SK, Kishan J, Raimondi S. Combined effect of GSTM1, GSTT1 and GSTP1 polymorphisms on histological subtypes of lung cancer. Biomarkers. 2008; 13:282-295.

21. Honma HN, De Capitani EM, Perroud MW Jr, Barbeiro AS, Toro IF, Costa DB, Lima CS, Zambon L. Influence of p53 codon 72 exon 4, GSTM1, GSTT1 and GSTP1*B polymorphisms in lung cancer risk in a Brazilian population. Lung Cancer. 2008; 61:152-162.

22. Chen HC, Cao YF, Hu WX, Liu XF, Liu QX, Zhang J, Liu J. Genetic polymorphisms of phase II metabolic enzymes and lung cancer susceptibility in a population of Central South China. Dis Markers. 2006; 22:141-152.

23. Ma DY, Du GB, Tan BX, Liu M, Zhao YL, Yang MH. Study on genetic polymorphism of GSTM1 and GSTT1 related with susceptibility to lung cancer in the population of northern Sichuan of China. Journal of cancer control and treatment. 2013; 26:136-139.

24. Wenzlaff AS, Cote ML, Bock CH, Land SJ, Schwartz AG. GSTM1, GSTT1 and GSTP1 polymorphisms, environmental tobacco smoke exposure and risk of lung cancer among never smokers: a population-based study. Carcinogenesis. 2005; 26:395-401.

25. Sørensen M, Autrup H, Tjønneland A, Overvad K, Raaschou-Nielsen O. Glutathione S-transferase T1 nullgenotype is associated with an increased risk of lung cancer. Int J Cancer. 2004; 110:219-224.

26. Ruano-Ravina A, Figueiras A, Loidi L, Barros-Dios JM. GSTM1 and GSTT1 polymorphisms, tobacco and risk of lung cancer: a case-control study from Galicia, Spain. Anticancer Res. 2003; 23:4333-4337.

27. Cajas-Salazar N, Sierra-Torres $\mathrm{CH}$, Salama SA, Zwischenberger JB, Au WW. Combined effect of MPO, GSTM1 and GSTT1 polymorphisms on chromosome aberrations and lung cancer risk. Int J Hyg Environ Health. 2003; 206:473-483.

28. Wang J, Deng Y, Cheng J, Ding J, Tokudome S. GST genetic polymorphisms and lung adenocarcinoma susceptibility in a Chinese population. Cancer Lett. 2003; 201:185-193.

29. Stücker I, Hirvonen A, de Waziers I, Cabelguenne A, Mitrunen K, Cénée S, Koum-Besson E, Hémon D, Beaune P, Loriot MA. Genetic polymorphisms of glutathione S-transferases as modulators of lung cancer susceptibility. Carcinogenesis. 2002; 23:1475-1481.

30. Zhao B, Seow A, Lee EJ, Poh WT, Teh M, Eng P, Wang YT, Tan WC, Yu MC, Lee HP. Dietary isothiocyanates, glutathione S-transferase $M 1, T 1$ polymorphisms and lung cancer risk among Chinese women in Singapore. Cancer Epidemiol Biomarkers Prev. 2001; 10:1063-1067.

31. Sharma N,Singh A,Singh N,Behera D, Sharma S. Genetic polymorphisms in GSTM1, GSTT1 and GSTP1 genes and risk of lung cancer in a North Indian population. Cancer Epidemiol. 2015; 39:947-955.
32. London SJ, Yuan JM, Chung FL, Gao YT, Coetzee GA, Ross RK, Yu MC. Isothiocyanates, glutathione S-transferase $M 1$ and $T 1$ polymorphisms, and lung-cancer risk: a prospective study of men in Shanghai, China. Lancet. 2000; 356:724-729.

33. Malats N, Camus-Radon AM, Nyberg F, Ahrens W, Constantinescu V, Mukeria A, Benhamou S, BaturaGabryel H, Bruske-Hohlfeld I, Simonato L, Menezes A, Lea S, Lang $\mathrm{M}$, et al. Lung cancer risk in nonsmokers and GSTM1 and GSTT1 genetic polymorphism. Cancer Epidemiol Biomarkers Prev. 2000; 9:827-833.

34. Salagovic J, Kalina I, Stubna J, Habalová V, Hrivnák M, Valanský L, Kohút A, Biros E. Genetic polymorphism of glutathione S-transferases M1 and T1 as a risk factor in lung and bladder cancers. Neoplasma. 1998; 45:312-317.

35. Saarikoski ST, Voho A, Reinikainen M, Anttila S, Karjalainen A, Malaveille C, Vainio H, HusgafvelPursiainen K, Hirvonen A. Combined effect of polymorphic GST genes on individual susceptibility to lung cancer. Int J Cancer. 1998; 77:516-521.

36. Jourenkova N, Reinikanen M, Bouchardy C, HusgafvelPursiainen K, Dayer P, Benhamou S, Hirvonen A. Effects of glutathione S-transferases GSTM1 and GSTT1 genotypes on lung cancer risk in smokers. Pharmacogenetics. 1997; $7: 515-518$.

37. To-Figueras J, Gené M, Gómez-Catalán J, Galán MC, Fuentes M, Ramón JM, Rodamilans M, Huguet E, Corbella J. Glutathione S-transferase M1 (GSTM1) and T1 (GSTT1) polymorphisms and lung cancer risk among Northwestern Mediterraneans. Carcinogenesis. 1997; 18:1529-1533.

38. Zhang H, Wu X, Xiao Y, Chen M, Li Z, Wei X, Tang K. Genetic polymorphisms of glutathione S-transferase M1 and T1, and evaluation of oxidative stress in patients with non-small cell lung cancer. Eur J Med Res. 2014; 19:67.

39. Pan C, Zhu G, Yan Z, Zhou Y, Liu Z. Glutathione S-transferase T1 and M1 polymorphisms are associated with lung cancer risk in a gender-specific manner. Oncol Res Treat. 2014; 37:164-169.

40. Piao JM, Shin MH, Kim HN, Cui LH, Song HR, Kweon SS, Choi JS, Kim YC, Oh IJ, Kim KS. Glutathione-Stransferase (GSTM1, GSTT1) null phenotypes and risk of lung cancer in a Korean population. Asian Pac J Cancer Prev. 2013; 14:7165-7169.

41. Sreeja L, Syamala V, Hariharan S, Syamala VS, Raveendran PB, Sivanandan CD, Madhavan J, Ankathil R. Glutathione S-transferase M1, T1 and P1 polymorphisms: susceptibility and outcome in lung cancer patients. J Exp Ther Oncol. 2008; 7:73-85.

42. Brennan P, Hsu CC, Moullan N, Szeszenia-Dabrowska N, Lissowska J, Zaridze D, Rudnai P, Fabianova E, Mates D, Bencko V, Foretova L, Janout V, Gemignani F, et al. Effect of cruciferous vegetables on lung cancer in patients stratified by genetic status: a Mendelian randomization approach. Lancet. 2005; 366:1558-1560. 
43. Cote ML, Kardia SL, Wenzlaff AS, Land SJ, Schwartz AG. Combinations of glutathione S-transferase genotypes and risk of early-onset lung cancer in Caucasians and African Americans: a population-based study. Carcinogenesis. 2005; 26:811-819.

44. Zhang JK, Hu YL, Hu CF, Wang SY. Study on genetic polymorphisms of GSTM1 and GSTT1 related with inherent susceptibility to lung cancer in women. Chinese Journal of Public Health. 2002; 18:273-275.

45. Cao YF, Chen HC and Liu XF. Study on the relationship between the genetic polymorphisms of GSTM1 and GSTT1 genes lung cancer susceptibility in the population of Hunan province of China. Life Sci Res. 2004; 8:126-128.

46. Qi XS, Lv HM, Xia Y, Shang B, et al. A primary casecontrol study on the relationship between genetic polymorphisms of GSTT1 and lung cancer susceptibility to the people living in high radon-exposed area. Chin Occup Med. 2008; 35:361-363, 367.

47. Fan J, Gan LG, Liang KC, Liang XM. Relationship of GSTM1 and GSTT1 genetic polymorphisms with lung cancer susceptibility in Guangxi Zhuang population. Journal of Oncology. 2010; 16: 922-925.

48. Yao W, Wang N, Wu YJ, Wu YM. Relationship between deletion of GSTM1, GSTT1 genes and susceptibility to lung cancer. Chinese Journal of Public Health. 2006; 22:1070 1072.

49. Sreeja L, Syamala V, Hariharan S, Madhavan J, Devan SC, Ankathil R. Possible risk modification by CYP1A1, GSTM1 and GSTT1 gene polymorphisms in lung cancer susceptibility in a South Indian population. J Hum Genet. 2005; 50:618-627.

50. Wang LI, Giovannucci EL, Hunter D, Neuberg D, Su L, Christiani DC. Dietary intake of Cruciferous vegetables, Glutathione S-transferase (GST) polymorphisms and lung cancer risk in a Caucasian population. Cancer Causes Control. 2004; 15:977-985.

51. Harms C, Salama SA, Sierra-Torres CH, Cajas-Salazar N, $\mathrm{Au}$ WW. Polymorphisms in DNA repair genes, chromosome aberrations, and lung Cancer. Environ Mol Mutagen. 2004; 44:74-82.

52. Dialyna IA, Miyakis S, Georgatou N, Spandidos DA. Genetic polymorphisms of CYP1A1, GSTM1 and GSTTl genes and lung cancer risk. Oncol Rep. 2003; 10:1829-1835.

53. el-Zein R, Zwischenberger JB, Wood TG, AbdelRahman SZ, Brekelbaum C, Au WW. Combined genetic polymorphism and risk for development of lung cancer. Mutat Res. 1997; 381:189-200.

54. Kelsey KT, Spitz MR, Zuo ZF, Wiencke JK. Polymorphisms in the glutathione S-transferase class mu and theta genes interact and increase susceptibility to lung cancer in minority populations (Texas, United States). Cancer Causes Control. 1997; 8:554-559.

55. Spitz MR, Duphorne CM, Detry MA, Pillow PC, Amos CI, Lei L, de Andrade M, Gu X, Hong WK, Wu X. Dietary intake of isothiocyanates: evidence of a joint effect with Glutathione S-Transferase polymorphisms in lung cancer risk. Cancer Epidemiol Biomarkers Prev. 2000;9:1017-1020.

56. Liang KC, Gan LG, Ruan L, Wei ZX, Liang XM, Ma Z. Correlational research of the relationship between the genetic polymorphism of GSTM1 and GSTT1 in the Zhuang population and lung cancer. Acta Medicine Sinic. 2012; 25:813-817.

57. Davey SG, Egger M. Meta-analyses of randomized controlled trials. Lancet. 1997;350:1182.

58. Higgins JP, Thompson SG, Deeks JJ, Altman DG. Measuring inconsistency in meta-analysis. Br Med J. 2003; 327:557-560.

59. DerSimonian R, Laird N. Meta-analysis in clinical trials. Control Clin Trials. 1986;7:177-88.

60. Mantel N, Haenszel W. Statistical aspects of the analysis of data from retrospective studies of disease. Natl Cancer Inst. 1959; 22:719-748.

61. Egger M, Smith DG, Schneider M, Minder C. Bias in metaanalysis detected by a simple, graphical test. Br Med J. 1997; 315:629-634.

62. Dual S, Tweedie R. A nonparametric "trim and fill" method of accounting for publication bias in meta-analysis. J Am Stat Assoc. 2000; 95:89-98.

63. Yang H, Shen X, Li B, Ma R. Association between glutathione S-transferase T1 null genotype and risk of lung cancer: a meta-analysis of 55 studies. Tumour Biol. 2014; 35:2359-2366.

64. Wang Y,Yang H, Li L, Wang H. Glutathione S-transferase $\mathrm{T} 1$ gene deletion polymorphism and lung cancer risk in Chinese population: a meta-analysis. Cancer Epidemiol. 2010; 34:593-597.

65. Higgins JPT, Green S. Cochrane handbook for systematic reviews of interventions version 5.0.1. The Cochrane Collaboration, Oxford. 2008.

66. Pan Z, Trikalinos TA, Kavvoura FK, Lau J, Ioannidis JP. Local literature bias in genetic epidemiology: an empirical evaluation of the Chinese literature. PLoS Med. 2005; 2:e334.

67. Li W, Yue W, Zhang L, Zhao X, Ma L, Yang X, Zhang C, Wang Y, Gu M. Polymorphisms in GSTM1, CYP1A1, CYP2E1, and CYP2D6 are associated with susceptibility and chemotherapy response in non-small-cell lung cancer patients. Lung. 2012; 190:91-98. 